\title{
Sugar Accumulation Enhanced by Osmoregulation in Satsuma Mandarin Fruit
}

\author{
Hiroshi Yakushiji ${ }^{1}$ \\ Akitsu Branch, Fruit Tree Research Station, Akitsu, Hiroshima 729-24, Japan \\ Hiroshi Nonami ${ }^{2,3}$ and Toshio Fukuyama ${ }^{2}$, \\ College of Agriculture, Ehime University, Tarumi, Matsuyama 790, Japan \\ Sukeyuki Ono ${ }^{1}$ \\ Akitsu Branch, Fruit Tree Research Station, Akitsu,Hiroshima 729-24, Japan \\ Nobuo Takagi ${ }^{1}$ \\ Ehime Prefecture Fruit Tree Experiment Station, Shimoidai, Matsuyama 791-01, Japan \\ Yasushi Hashimoto ${ }^{4}$ \\ College of Agriculture, Ehime University, Tarumi, Matsuyama 790, Japan \\ Additional index words. water stress, turgor maintenance, Citrus fruit, mulch
}

\begin{abstract}
The effect of water stress induced to enhance sugar accumulation in Satsuma mandarin (Citrus unshiu Marc.) fruit was investigated. Satsuma mandarin trees were subjected to water stress using mulch cultivation from late August to early December. In mulch treatment, soil was covered with double-layered plastic sheets that prevented rainfall from permeating the soil, but allowed water from soil to evaporate. The water status of soil, fine roots, pericarps, and juice vesicles was determined using the isopiestic psychrometer. As the severity of water stress increased, both water potential and osmotic potential of fine roots and pericarps significantly decreased in plants grown under mulch cultivation compared to well-watered trees. Although water potential and osmotic potential decreased, turgor of both roots and pericarps of the water stressed trees did not decrease under water stress conditions. Because turgor was maintained, osmoregulation occurred in Satsuma mandarin trees in response to water stress. The osmotic potential of juice vesicles in water-stressed fruit gradually decreased, and sugars accumulated in vesicle cells. Concentrations of sucrose, fructose, and glucose increased in fruit sap under water stress, and the acidity in the fruit juice increased. Furthermore, the total sugar content per fruit of water stressed trees was significantly higher than in fruit of well-watered trees. These results suggest that sugar accumulation in Satsuma mandarin fruit was not caused by dehydration under water stress but rather that sugars were accumulated by active osmoregulation in response to water stress. When sugar components in osmoregulated fruit were analyzed, it was found that monosaccharides, i.e., glucose and fructose, were largely responsible for active osmoregulation in fruit under water stress conditions.
\end{abstract}

Concentrations of sugars and organic acids determine the taste of Satsuma mandarin fruit. In recent years, Japanese citrus growers have increased the use of mulch cultivation or greenhouse cultivation to produce high quality citrus fruit. Although there have been a few approaches to investigate the mechanism of sugar accumulation induced by water stress in Satsuma mandarin fruit (Kadoya, 1972, 1973; Sugai and Torikata, 1976), physiological mechanisms of water stress on Satsuma mandarin fruit have not been studied critically from the perspective of plant-water relations.

Meyer and Boyer (1981) found that water stress triggers the physiological function of osmoregulation. Osmoregulation involves solute accumulation in cells sufficient to decrease the osmotic potential of cells when water potential of cells decreases at low water potential of the water source so that water can be absorbed from the water source by cells without losing cell turgor or decreasing cell volume. Many plants, to tolerate water stress, are largely dependent on their capacity for osmoregulation for

Received for publication 3 Jan. 1995. Accepted for publication 8 Aug. 1995. Contribution no. E-184 of the Fruit Tree Research Station.The cost of publishing this paper was defrayed in part by the payment of page charges. Under postal regulations, this paper therefore must be hereby marked advertisement solely to indicate this fact.

${ }^{1}$ Agricultural research scientist.

${ }^{2}$ Associate professor.

${ }^{3}$ To whom reprint requests should be addressed.

${ }^{4}$ Professor. maintaining cell turgor through the accumulation of solutes (Morgan, 1984). Osmoregulation has been observed in stems (Meyer and Boyer, 1981; Nonami and Boyer, 1989; Westgate and Boyer, 1985), roots (Sharp and Davies, 1979; Westgate and Boyer, 1985) and leaves (Cutler et al., 1977; Cutler et al., 1980; Westgate and Boyer, 1985). Water-stressed plants accumulate more sugars than unstressed plants (Meyer and Boyer, 1981; Timpa et al., 1986). However, only limited information is available concerning the component of water potential in citrus trees under water stress for osmoregulation (Kaufmann, 1970; Yakushiji et al., 1992). Little is known about the relationship between the sugar accumulation of fruit and osmoregulation in Satsuma mandarin.

Water-stressed plants tend to yield smaller fruit in citrus trees although sugars accumulate in the fruit. Because citrus fruit have stomata on the pericarp surfaces, sugar accumulation may be induced by dehydration due to transpiration from fruit under water stress conditions. Thus, concentrations of sugars in fruit can be increased due to loss of water from cells in fruit. To check the possibility of dehydration in fruit under water stress conditions, the turgor of pericarp cells and juice vesicles was measured using the psychrometer. If fruit dehydrate during water-stress conditions, then the fruit's cell turgor should decrease as well.

If solute accumulation is related to inhibition of growth in fruit during water stress, solutes accumulated in fruit must have originated from materials of cell walls and membranes that are supposedly used for cell expansion. In the case of soybean plants, it was 
found that sugars and amino acids were accumulated in cells of the elongation zone when growth was inhibited at low water potentials (Meyer and Boyer, 1981). Such solute accumulation may not be the case in Satsuma mandarin fruit, because fruit always accumulate sugars during the processes of growth and ripening. To test whether sugars can be actively accumulated in Satsuma mandarin fruit during water stress conditions, the Satsuma mandarin fruit used in the present study were grown to similar size in both wellwatered and water-stressed plants by adjusting the number of fruit in trees. Fruit thinning is used as a conventional cultivation method in Japan to improve the quality of fruit. If active solute accumulation is taking place in Satsuma mandarin fruit during water stress conditions, concentrations of solutes in fruit produced under water stress conditions must be significantly higher than in fruit produced in well-watered plants when the size of fruit is the same in both treatments.

Thus, we investigated the relationship between osmoregulation and the sugar accumulation in fruit by measuring the water status of tissues while Satsuma mandarin were subjected to water stress using mulch cultivation. Also, we analyzed soluble solid concentrations measured with Brix refractometers and compared this with osmotic potentials measured using isopiestic psychrometry.

\section{Materials and Methods}

Plant materials. Experiments were performed on twenty 13year-old Satsuma 'Nankan 20-Gou' mandarin trees (Citrus unshiu Marc.) grafted on Poncirus trifoliata rootstocks at Ehime experimental station orchard in 1991. The flowering season of Satsuma mandarin is about the middle of May, and fruit are harvested from late November to early December. Before mulch treatment, all trees were thinned to one fruit per 25-30 leaves in early August, when average fruit size varied from 20-30 g. Mulch cultivation was accomplished by laying micro-perforated vinyl sheets (Tyvek, DuPont) on the orchard floor of 10 trees for about 4 months beginning from early August to early December after stopping irrigation. Tyvek is made of double-layered films and has polarity for water permeation. Rainfall is impermeable through the film, while water vapor from soil can escape so that the soil where the mandarin trees were grown could be dried during mulch treatment under field conditions. Plant tissues of mulched (water-stressed) and control (well-watered) trees were collected to measure their water status, sugar, and acid contents.

Water status measurement. The water status of plant tissues and soil was determined using the isopiestic psychrometer (Boyer and Knipling, 1965). Soil, fine roots, pericarps, and vesicles were sampled at predawn (i.e., between 5 and 6 AM) to minimize the effect of transpiration on the water status of plants. About $500 \mathrm{mg}$ of soil were sampled at a depth of $20 \mathrm{~cm}$ from the soil surface at two to three locations under the canopy. Four fine roots $1.5 \mathrm{~cm}$ long were collected at the same place where the soil was sampled. The roots were placed on the bottom of the psychrometer sampling cup. More than five fruit were collected at the middle of outer side of the canopy for each sampling. The area of about $1.0 \mathrm{~cm}^{2}$ of pericarp was excised from a fruit and placed on the bottom of the sampling chamber immediately after excision. Three juice vesicles extracted from a fruit, and their surface was wiped off with tissue paper. Before the sampling, thermocouple chambers were coated with melted and resolidified petrolatum (Boyer, 1967). The chambers were loaded with plant tissues immediately after their excision or isolation. Immediately after water potential measurements, osmotic potentials were determined on the same tissues by freezing at $-70 \mathrm{C}$ and thawing them at 25C, respectively (Ehlig, 1962;
Nonami et al., 1987). Turgor was calculated by subtracting the osmotic potential from the water potential (Nonami et al., 1987).

Soluble solid concentration measurement. Soluble solid concentrations (SSC) were evaluated on five fruit per treatment using a refractometer (ATAGO Hand Refractometer N-1, Honcho, Itabashi-ku, Tokyo) at each sampling time. The SSC was expressed according to the refractometer index (\%), which was defined as the percentage of solute weight divided by the weight of the solution. The refractometer was calibrated using sucrose solutions of known concentrations. The percentage scale of the ATAGO Hand Refractometer indicates grams of sucrose in $100 \mathrm{~g}$ of sucrose solution. Immediately after cutting a fruit in half, the juice was squeezed onto the reflector of the refractometer, and SSC values were read directly from the refractometer. To examine the relationship between SSC and the water potentials of sucrose, fructose, glucose, citric acid, the SSC, and the osmotic potential were determined by a refractometer and an isopiestic psychrometer at $25 \mathrm{C}$ in the same sample.

Sugar component and acidity analysis. In order to investigate the effect of water stress on sugar accumulation in fruit, the composition of sugars in fruit was analyzed using 7 fruit $(x=119.0$ $\pm 9.1 \mathrm{~g}, \mathrm{n}=7$ for mulch-grown plants; $\mathrm{x}=119.2 \pm 5.6 \mathrm{~g}, \mathrm{n}=7$ for well-watered plants) obtained from both water-stressed and wellwatered trees at harvest time on 9 Dec. HPLC was used to identify and quantify the sugars in the fruit. About $20 \mathrm{~g}$ of pulp was homogenized for 5 min with a Polytron homogenizer (Brinkman Instruments, Westburg, N.Y.) in 10 volumes of $80 \%$ (by volume) ethanol. The extract was filtered through a Whatman glass microfibre filter, rinsing the insolubles with the above solution. In order to concentrate the filtrated solution, the filtrate was evaporated on a rotary evaporator (RE-2, Tokyo Rika Kikai Co., Tokyo) at 36C under reduced pressure. The concentrated solution was filtrated through a $0.45-\mu \mathrm{m}$ filter (Waters, Millipore Corp., Milford, Mass.). A 10- $\mu$ l sample was injected into the HPLC (LC-3A; Shimadzu) equipped with a refractive index detector (RID-2A; Shimadzu). Sugars were separated using a SCR-101N column (Shimadzu) maintained at $60 \mathrm{C}$ and water as solvent at a flow rate of $1.0 \mathrm{ml} / \mathrm{min}$. Sucrose, glucose, and fructose were identified and quantified by comparison with peaks produced by a known standard sugar solution with a reporting integrator (C-R2X, Shimadzu). Titratable acidity was determined for each fruit juice by titration using $0.1 \mathrm{~N} \mathrm{NaOH}$ with an endpoint of $\mathrm{pH} 8.1$ and converted to citric acid concentrations in fruit. Because citric acid has molecular weight of 192.12 with 3 -COOHs, one equivalent gram of citric acid is $192.12 / 3=64.04 \mathrm{~g}$, and thus, $1.0 \mathrm{ml}$ of $0.1 \mathrm{~N} \mathrm{NaOH}$ is equivalent to $6.40 \mathrm{mg}$ of citric acid. The similar conversion was confirmed in juice of several varieties of oranges and mandarins (Chachin, 1986; Sinclair, 1961).

\section{Results and Discussion}

The effect of water stress on water status of soil and root tissues. When soil was covered with Tyvek film, water potential of soil where plants were grown in the mulch treatment became much lower than in the well-watered treatment (Fig. 1). Heavy rainfall due to a typhoon caused a temporary increase in soil water potential of mulch treatment in late September. Rain water seeped into soil through joining parts of Tyvek sheets. However, the soil water potential under mulch treatment ranged from -0.90 to -1.80 $\mathrm{MPa}$, whereas that of the control ranged from -0.02 to $-0.27 \mathrm{MPa}$ (Fig. 1). Simultaneously with soil water potential measurements, the water status of fine roots and pericarp of fruit was measured at predawn during the mulch treatment. Fine roots in the control 


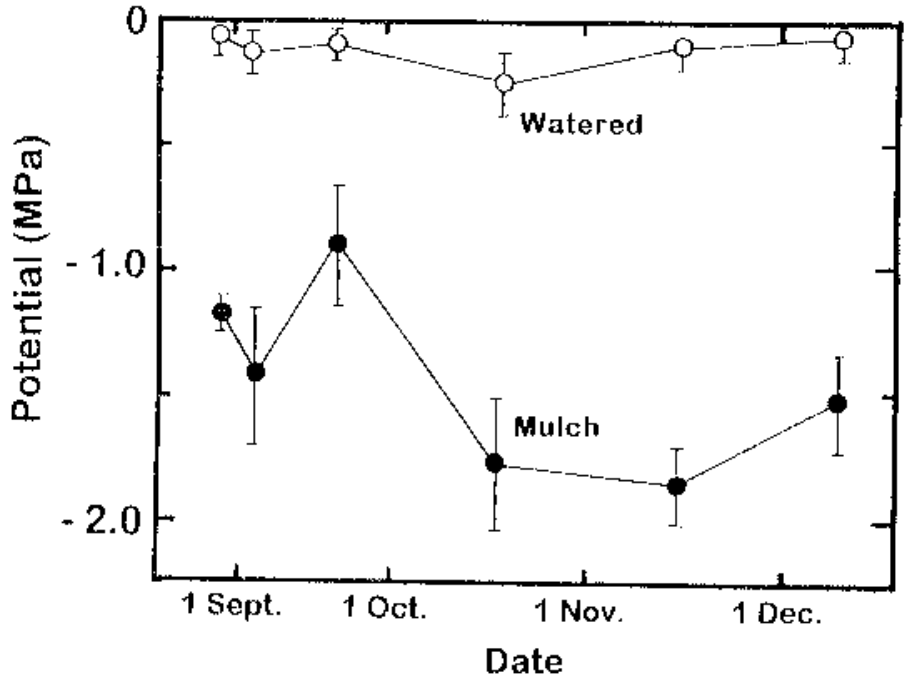

Fig. 1. Seasonal changes in water potential of the soil where Satsuma mandarin trees were grown under well-watered $(\bigcirc)$ and mulch-grown $(\bullet)$ conditions. Soil samples were taken $20 \mathrm{~cm}$ below the soil surface at two to four locations under the canopy and water potentials were measured using isopiestic psychrometers. Each point is the mean of two to four observations \pm standard deviation.

plants had slightly lower water potentials than the water potential of the soil surrounding them (Figs. 1 and 2A). Water potentials of the fine roots of the mulch-grown plants ranged from -1.1 MPa to $-1.5 \mathrm{MPa}$ (Fig. 2A) and were higher than the water potential of the surrounding soil in October and November (Figs. 1 and 2A). This suggested that water could be relocated from deeper location in the soil to roots located near the soil surface. Even though water potential of soil for the mulch treatment was $1.0 \mathrm{MPa}$ drier than the control (Fig. 1), turgor of fine roots of mulch-grown plants was maintained above $0.4 \mathrm{MPa}$ (Fig. 2B). The turgor of the fine roots in the mulch treatment became slightly lower than the turgor of fine

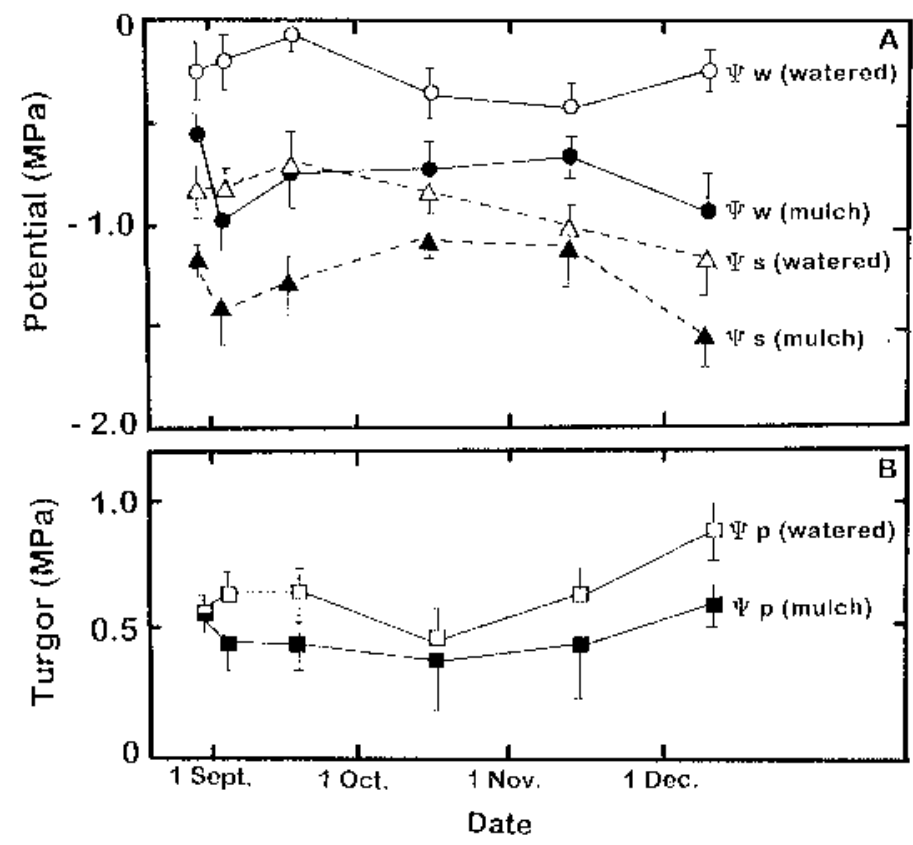

Fig. 2. Seasonal changes in $(\mathbf{A})$ water potential $(\Psi \mathrm{w} ; \bigcirc, \bigcirc)$ and osmotic potential $(\Psi \mathrm{s} ; \boldsymbol{\Lambda}, \Delta)$, and $(\mathbf{B})$ turgor $(\Psi \mathrm{p} ; \boldsymbol{\square}, \boldsymbol{\square})$ of fine roots of Satsuma mandarin trees at $20 \mathrm{~cm}$ below the soil surface. Open symbols $(\bigcirc, \Delta, \square)$ indicate roots taken from well-watered trees and closed symbols $(\boldsymbol{O}, \boldsymbol{\Delta}, \mathbf{\square})$ indicate roots taken from mulchgrown trees. Each point is the mean of two to four observations \pm standard deviation.

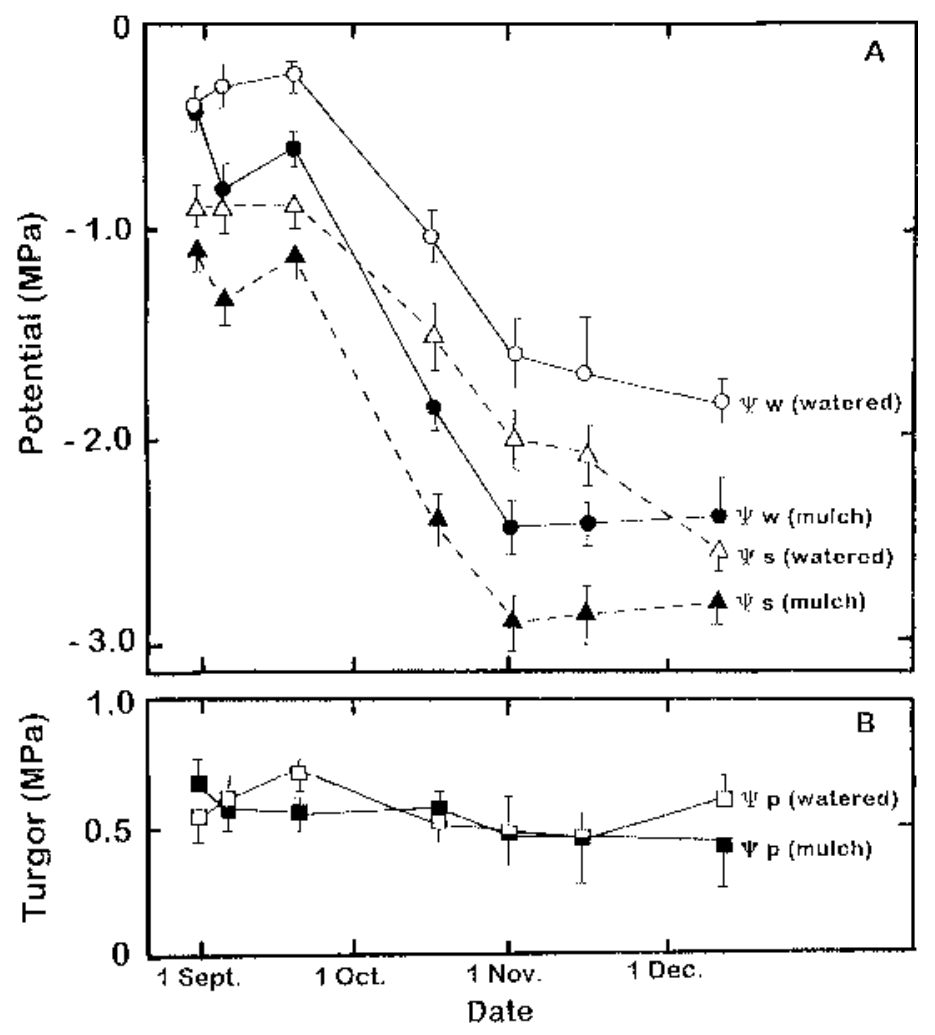

Fig. 3. Seasonal changes in (A) water potential $(\Psi \mathrm{w} ; \bigcirc, \bigcirc)$ and osmotic potential $(\Psi \mathrm{s} ; \boldsymbol{A}, \Delta)$, and $(\mathbf{B})$ turgor $(\Psi \mathrm{p} ; \boldsymbol{\square}, \square)$ of pericarp of Satsuma mandarin fruits. Open symbols $(\bigcirc, \Delta, \square)$ indicate pericarp of fruits formed in well-watered trees and closed symbols $(\boldsymbol{O}, \mathbf{\Delta}, \mathbf{\square})$ indicate pericarp of fruits formed in mulch-grown trees. Each point is the mean of two to three observations \pm standard deviation.

roots of well-watered plants (Fig. 2B). The decrease in water potential of the fine roots of mulch-grown plants was compensated by a coincidental decrease in osmotic potential of the fine roots (Fig. 2A), resulting in turgor maintenance of the fine roots (Fig. 2B). Thus, osmoregulation was occurring in the fine roots when water potential of soil decreased due to mulch treatment.

Water relations of fruit. Water potential of fruit pericarp produced in the well-watered plants began to decrease in October and went down to -1.8 MPa in December (Fig. 3A), although the water potential of soil and fine roots did not decrease (Figs. 1 and 2A). The decrease in water potential of the pericarp of the control plants was not related to water stress, but to the ripening process of fruit.

Water potential of the fruit pericarp produced in the mulchgrown plants began to decrease from October, and was continuously 0.5-0.7 MPa lower than that in the control plants (Fig. 3A). The decrease in water potential was compensated by a decrease in osmotic potential in both treatments (Fig. 3A). Thus, the turgor of pericarp of fruit produced in the mulch-grown plants was similar to that of the control plants under water stress conditions (Fig. 3B). Because turgor was maintained while water potential became lower, it was apparent that significant dehydration in pericarp cells was not taking place during the mulch treatment. If dehydration had taken place significantly from pericarp cells, turgor would have also been lost significantly due to a decrease in cell volume in pericarp cells during mulch treatment because changes in relative cell volume $(\Delta \mathrm{V} / \mathrm{V})$ must be in positively direct proportion to changes in cell turgor $\left(\Delta \Psi_{\mathrm{p}}\right)$ by cell wall bulk compliance $(\mathrm{B})$, i.e., $\Delta \mathrm{V} / \mathrm{V}=\mathrm{B} \Delta \Psi_{\mathrm{p}}$ (Nonami and Boyer, 1990). Because osmotic potential of mulch-grown plants was significantly lower than wellwatered plants (Fig. 3A), the decrease of osmotic potential was 


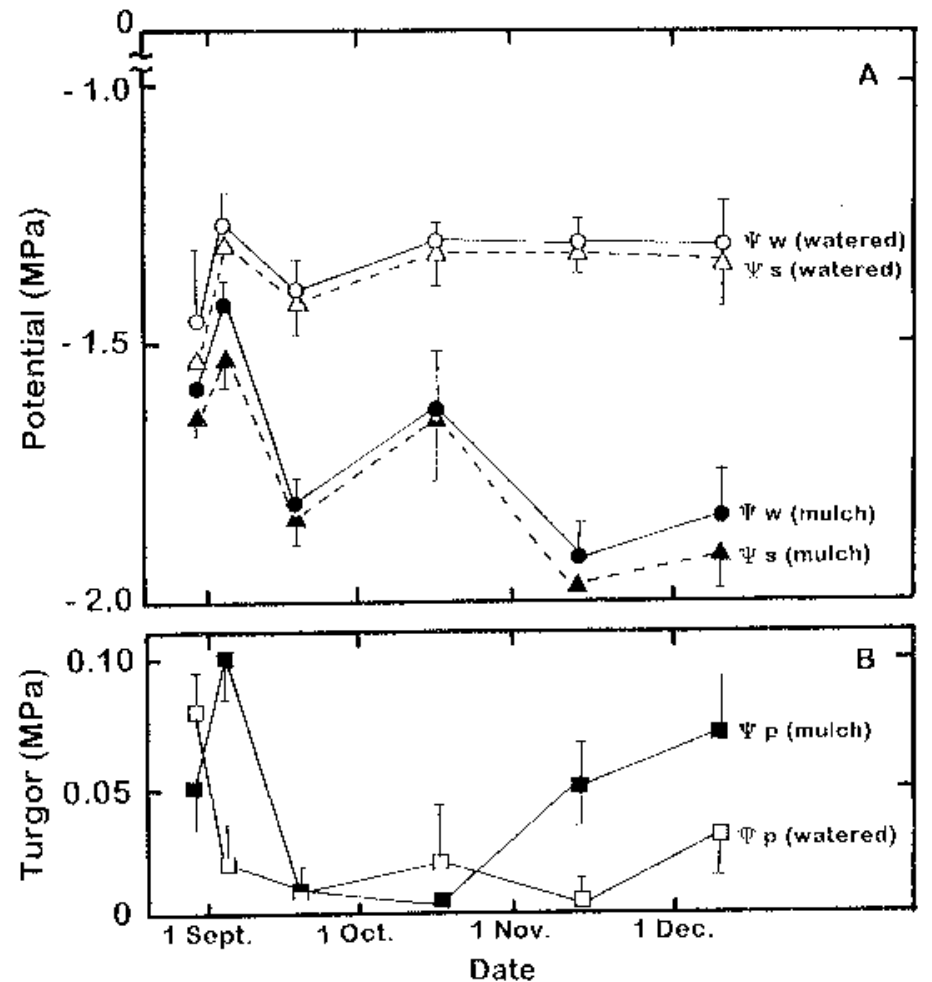

Fig. 4. Seasonal changes in (A) water potential $(\Psi \mathrm{w} ; \bigcirc, \bigcirc)$ and osmotic potential $(\Psi \mathrm{s} ; \boldsymbol{\Lambda}, \Delta)$, and $(\mathbf{B})$ turgor $(\Psi \mathrm{p} ; \boldsymbol{\square}, \boldsymbol{\square})$ of vesicles of Satsuma mandarin fruits. Open symbols $(\bigcirc, \Delta, \square)$ indicate vesicles isolated from fruits formed in well-watered trees, and closed symbols $(\boldsymbol{O}, \boldsymbol{\Lambda}, \boldsymbol{\square})$ indicate vesicles isolated from fruits formed in mulch-grown trees. Each point is the mean of two to three observation \pm standard deviation.

caused not only by the ripening process of fruit but also by active accumulation of solutes. Therefore, osmoregulation actively occurred in the pericarp of fruit produced in the mulch-grown plants.

Fruit juice vesicles were isolated from fruit pulp without damaging vesicle membranes, and water potential of juice vesicles was measured. In the well-watered control plants, water potential of fruit juice vesicles was lower than that of fruit pericarp in September and October. Starting in November, the water potential of juice vesicles was higher than that of fruit pericarp (Figs. 3A and $4 \mathrm{~A})$. When the soil was covered with mulch, water potential of juice vesicles began to decrease gradually (Fig. 4A). Although water potential of the juice vesicles of the mulch-grown plants decreased as the soil water potential decreased (Figs. 1 and 4A), turgor of fruit vesicles was generally larger in the mulch-grown plants than in well-watered plants (Fig. 4B). Because osmotic potential of juice vesicles in mulch-grown plants was significantly lower than in well-watered plants (Fig. 4A), osmotically active solutes accumulated significantly more in juice vesicles in mulchgrown plants than in well-watered plants. Because turgor of juice vesicles at harvest time was larger in mulch-grown plants than in well-watered plants (Fig. 4B), juice vesicles may be more turgid in mulch-grown plants than in well-watered plants. These results indicate that osmoregulation actively occurred in fruit juice vesicles under mulch treatment.

The SSC in fruit produced in the mulch-grown plants increased as the water potential and osmotic potential of fruit vesicles decreased (Figs. 4A and 5). Because the SSC indicates cell solution concentration, the decrease in osmotic potential indicates accumulation of solutes in fruit vesicle cells. Osmotic potential measured with psychrometers was compared with osmotic potential of cell sap extracted from tissue using osmometers. Because both values

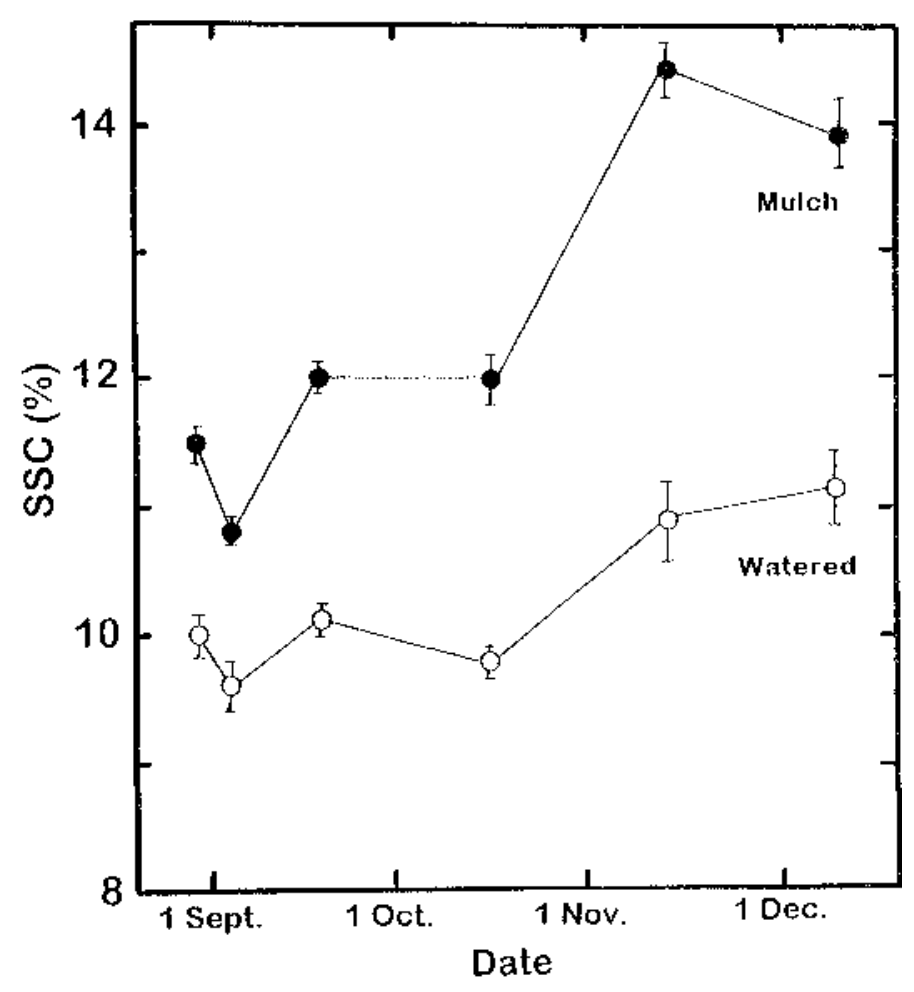

Fig. 5. Seasonal changes in soluble solid concentration (SSC) measured as \% solutes of the fruit juice extracted from fruits formed in mulch-grown $(\bullet)$ and well-watered (O) Satsuma mandarin trees. The SSC was measured by using a refractometer. Each point is the mean of five observations \pm standard deviation.

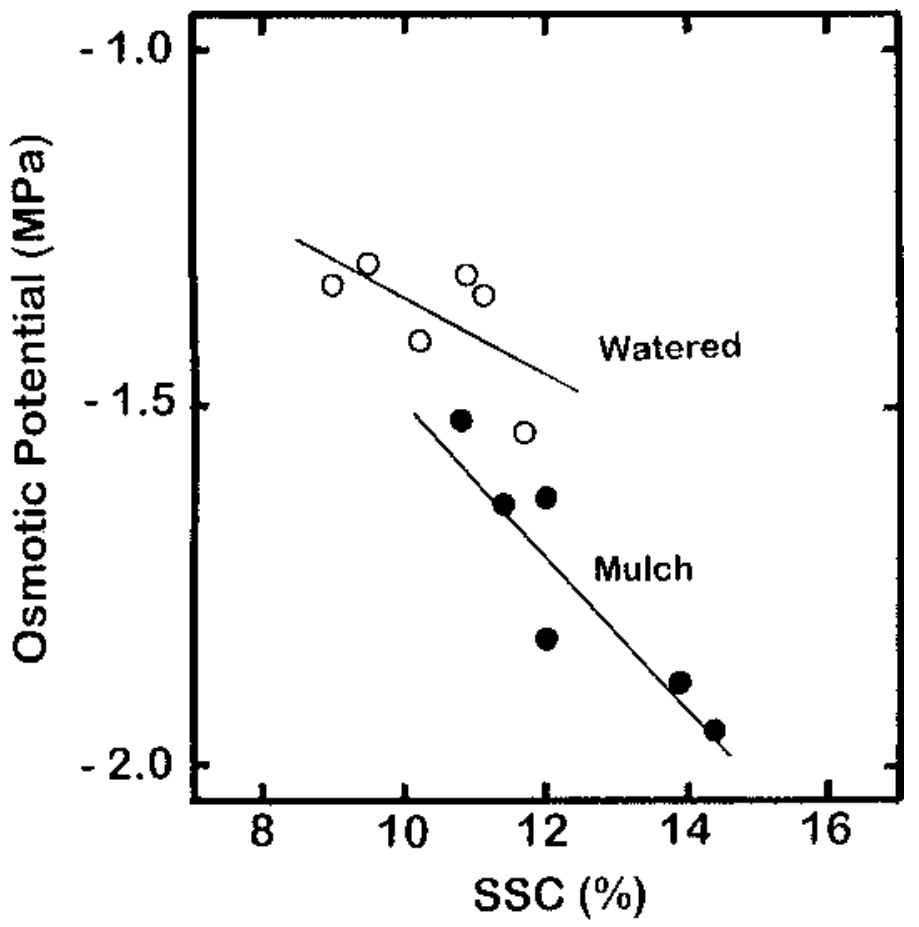

Fig. 6. Relationship between soluble solid concentration (SSC) and osmotic potential of vesicles from fruits formed in well-watered $(\bigcirc)$ and mulch-grown $(\bullet)$ Satsuma mandarin trees. The regression equation for osmotic potential as a function of SSC for fruit in well-watered treatment is $\mathrm{y}=-0.814-0.054 \mathrm{x}\left(r^{2}=0.36\right)$, and $\mathrm{y}=-0.382$ $-0.109 \mathrm{x}\left(r^{2}=0.85\right)$ for fruit in mulch treatment. Each plot represents data collected from fruits produced in well-watered and mulch-grown Satsuma mandarin trees and collected between 28 Aug. and 9 Dec. 1991. 
Table 1. Effect of water stress induced by mulching on concentrations of sugars and acidity of Satsuma mandarin fruit.

\begin{tabular}{|c|c|c|c|c|c|c|c|c|}
\hline \multirow[b]{2}{*}{ Treatment $^{\mathrm{z}}$} & \multirow[b]{2}{*}{ Fruit $^{\mathrm{y}}$ weight (g) } & \multirow[b]{2}{*}{ Pulp $^{\mathrm{x}}$ weight $(\mathrm{g})$} & \multicolumn{4}{|c|}{ Sugar concn $(\mathrm{mM})$} & \multirow{2}{*}{$\begin{array}{l}\text { Total sugar content } \\
\text { per pulp (mmol/pulp) }\end{array}$} & \multirow{2}{*}{$\begin{array}{r}\text { Acidity }^{\mathrm{w}} \\
(\mathrm{mM})\end{array}$} \\
\hline & & & Sucrose & Glucose & Fructose & $\overline{\text { Total sugar }}$ & & \\
\hline Mulch & $119.0 \pm 9.1$ & $91.6 \pm 7.0$ & $214 \pm 11$ & $116 \pm 4$ & $171 \pm 13$ & $501 \pm 22$ & $45 \pm 2$ & $40 \pm 1$ \\
\hline Watered & $119.2 \pm 5.6$ & $91.2 \pm 4.3$ & $174 \pm 11$ & $87 \pm 8$ & $122 \pm 10$ & $383 \pm 27$ & $35 \pm 3$ & $36 \pm 2$ \\
\hline Significance & NS & NS & $*$ & $* *$ & $* *$ & $* *$ & $* *$ & $* *$ \\
\hline
\end{tabular}

${ }^{\mathrm{z}}$ Values represent the mean \pm the standard error $(\mathrm{n}=7)$.

'Sampled on 9 Dec. 1991.

xulp indicates fruit whose pericarp was removed.

${ }^{\mathrm{w}}$ Acidity is expressed as mmol of citric acid per liter of fruit juice.

Ns,*,**Nonsignificant or significant at $P=0.05$ or 0.01 by Student's $t$ test, respectively.

were similar (Hashimoto and Nonami, 1990; Nonami and Schulze, 1989), decreases in osmotic potential measured with psychrometers indicate increases in concentrations of osmotically active solutes in cells. Measurements of SSC with the refractometer confirmed active accumulation of osmotically active solutes in fruit vesicle cells.

When the osmotic potential of fruit juice vesicles was plotted as a function of SSC, the fruit juice extracted from mulch-grown plants exhibited a steeper slope than fruit juice extracted from wellwatered plants (Fig. 6). At the same SSC value, the osmotic potential of the fruit juice extracted from mulch-grown plants was lower than that of the fruit juice extracted from well-watered plants. The chemical composition of fruit juice extracted from mulch-grown plants was different from the fruit juice extracted from well-watered plants.

Because the growth of fruit was adjusted by reducing the number of fruit per tree, the weight of individual fruit produced in mulch-grown plants was similar to that of fruit produced in well watered plants. We analyzed the sugar components and acidity in fruit of similar size collected from mulch-grown and well-watered trees at harvest time. Fruit produced in the mulch-grown plants had higher concentrations of sucrose, glucose, and fructose (Table 1). The sugar content per fruit without pericarp was significantly larger in mulch-grown plants than in well-watered plants (Table $1)$. The acidity in fruit produced in mulch-grown plants was slightly higher than that in fruit produced by well-watered plants (Table 1). These results indicate that water stress induced by mulching increased not only concentrations of sucrose, glucose, and fructose but also the absolute sugar content in the fruit.

Relationship between refractometer measurements and psychrometer measurements. The quality of fruit is frequently evaluated by measuring SSC with a refractometer. The measurements can be done quickly, and refractometers are available at low cost. The SSC of Satsuma mandarin fruit is known to consist mainly of sugars (i.e., sucrose, fructose, and glucose) and citric acid (Daito and Sato, 1985). The refractometer was calibrated using sucrose solutions of known concentrations, and the percentage scale indicates gram of sucrose in $100 \mathrm{~g}$ of sucrose solution. Because the relative specific refractivity of sucrose is 1.031 (Wolf et al., 1980), the weight percentage of sucrose exhibits a 1:1 relation with SSC of sucrose as defined for the refractometer scale when the refractometer was calibrated (data are not shown). Similarly, because the relative specific refractivity of fructose and glucose is 1.021 and 1.031, respectively (Wolf et al., 1980), the weight percentage of fructose and glucose exhibited a 1:1 relation with SSC (data not shown). Because the relative specific refractivity of citric acid is 0.951 (Wolf et al., 1980), the weight percentage of citric acid deviated from a 1:1 relation with SSC, and its slope was slightly steeper than the regression equation of sucrose, fructose, and glucose against SSC when it was calibrated (data not shown).
To compare SSC values measured in solution made from single chemicals with SSC values measured in Satsuma mandarin fruit, water potential of solution was converted to osmotic pressure, assuming that solutions were contained in the ideal osmometer. Also, the absolute value of osmotic potential measured in fruit vesicles was assumed to be equivalent to values of osmotic pressure of fruit vesicle cells having the ideal semipermeable membrane.

We examined the relationship between the SSC measured with the refractometer, and the osmotic pressure of sucrose, fructose, glucose, and citric acid solutions made from commercially available chemicals. When osmotic pressure of citric acid, glucose, fructose, and sucrose solution was plotted against SSC, osmotic pressure of the citric acid solution showed a linear relationship with SSC and a similar slope as glucose and fructose against SSC (Fig. 7). The slope of osmotic pressure of sucrose solution against SSC exhibited about half of the steepness of the slope of fructose, glucose, and citric acid (Fig. 7). Because osmotic pressure indicates the chemical potential of water, the quotient of SSC divided by molecular weight of solutes is related with activity of water in solution. Therefore, the quotient of SSC divided by molecular weight of solutes is proportional to molar concentrations of solutes in solution. Thus, SSC values measured with the refractometer are indicating the weight of solute contained in solution per unit volume of solution.

Because there are many kinds of solutes mixed together in fruit cells, the interpretation of SSC measured in Satsuma mandarin fruit may not be so simple. SSC measured with Satsuma mandarin fruit was located between the line formed by sucrose and the line formed by citric acid and monosaccharides (i.e., glucose and fructose) (Fig. 7). The line of the well-watered plants was located closer to that of sucrose, and the line of the mulch-grown plants was located closer to that of the monosaccharides (Fig. 7). This indicated that smaller sized molecules tended to accumulate when SSC increased as osmotic pressure increased. Thus, smaller sized molecules were contributing to high osmotic pressure in cells. This idea was supported by the analysis of sugar concentrations in fruit shown in Table 1. Mulch-grown plants accumulated glucose and fructose significantly more than well-watered plants, although sucrose and citric acid also accumulated more in mulch-grown plants than well-watered plants.

The effect of dehydration on fruit during mulching cultivation. Sugar accumulation can be expected in Satsuma mandarin fruit if the fruit juice is concentrated by dehydration (Sugai and Torikata, 1976). If so, the total sugar content per fruit must be equal, because only water must be lost from fruit during the process of dehydration. In order to test such a possibility, the sugar content in the equal-sized fruit were analyzed to compare water-stressed and control plants at the harvest time (Table 1). Water stress that increased the concentration of sucrose, fructose and glucose was found to result in higher total sugar content in fruit than those of the 


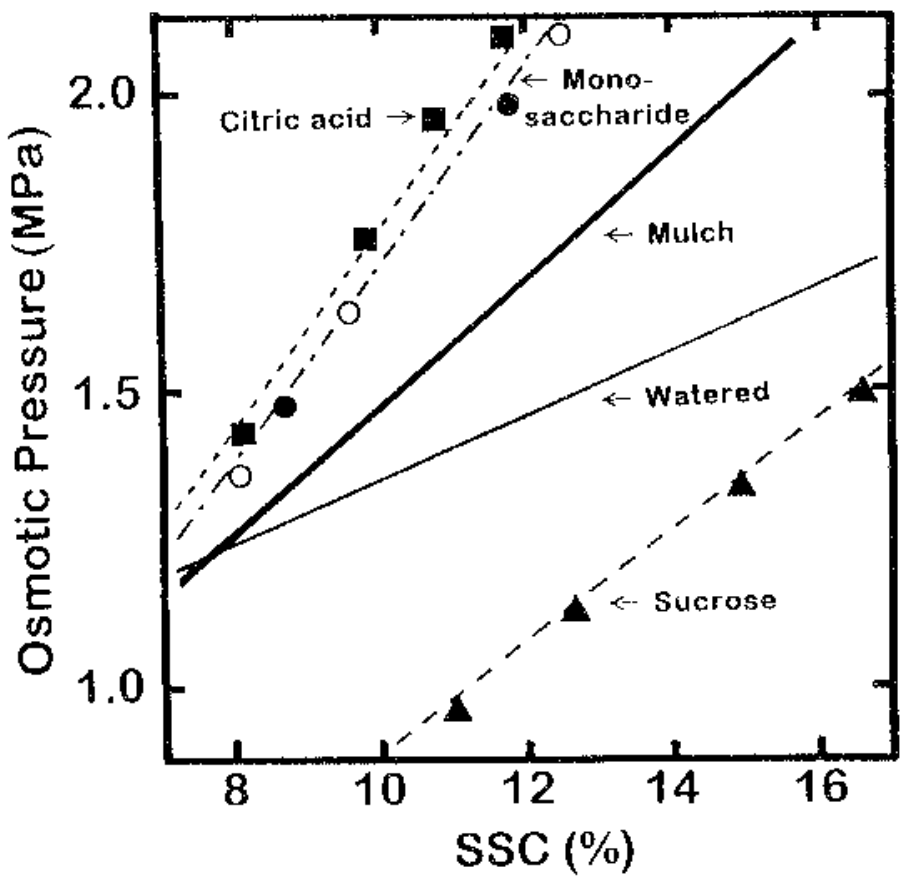

Fig. 7. Osmotic pressure of Satsuma mandarin fruit vesicles of mulch-grown and well-watered trees, citric acid, monosaccharide (i.e., glucose and fructose) and sucrose solutions as a function of soluble solid concentration (SSC). Regression equations were as follows; citric acid $(\boldsymbol{\square})$ : $\mathrm{y}=0.178 \mathrm{x}, r^{2}=0.99$; monosaccharide [glucose (O) and fructose $(\boldsymbol{O})$ ]: $\mathrm{y}=0.170 \mathrm{x}, r^{2}=0.99$; sucrose $(\boldsymbol{\Delta}): \mathrm{y}=0.091 \mathrm{x}$, $r^{2}=0.99$. Data for citric acid, glucose, fructose and sucrose were obtained using commercially available chemicals. Equations for mulch-grown (thick solid line: $\left.\mathrm{y}=0.109 \mathrm{x}+0.382 ; r^{2}=0.85\right)$ and well-watered (thin solid line: $\mathrm{y}=0.054 \mathrm{x}+$ $\left.0.814 ; r^{2}=0.36\right)$ trees are replotted from Fig. 6 using the concept of an ideal osmometer as discussed in the text.

control. Moreover, the total sugar content of water-stressed fruit was significantly higher than in well-watered fruit. Therefore, dehydration is not sufficient to explain the mechanism of sugar accumulation in fruit under water stress.

If significant dehydration occurs due to water stress, water must be lost from cells, and therefore, shrinkage of cells can be expected to occur, resulting in decreases in cell turgor. When the water status of juice vesicles was measured, vesicle turgor was maintained at positive pressure under water stress (Fig. 4B).

Although vesicle turgor was lower than $0.05 \mathrm{MPa}$ from late September to middle October, the vesicle turgor of mulch-grown trees was almost the same as that of well-watered trees. Therefore, the cell volume of vesicles in both treatments is considered not to be changed by dehydration. Data indicating low turgor may be explained by a rapid increase in vacuolation of vesicle cells during this period and also the existence of thin-walled cells in mature fruit (Nii, 1988).

Mechanisms of osmoregulation in Satsuma mandarin fruit. In the present study, the size of fruit was adjusted using a fruitthinning technique. Because fruit weight was 20-30 g when fruit was thinned, cell division and organ formation in fruit could be considered almost completed before mulch treatment. The growth of fruit was mainly dependent on cell expansion in both wellwatered control and mulch-grown trees. The sugar analysis and water status measurements in the present study demonstrate monosaccharides to be active components of fruit for osmoregulation. Because sucrose is the primary substance for translocation and phloem unloading in citrus plants (Kriedemann, 1969; Sawamura et al., 1975), degradation of sucrose to fructose and glucose must be promoted in vesicle cells during the process of active osmoregulation in Satsuma mandarin fruit.

During osmoregulation under water stress, cells must rely on imported solutes to lower osmotic potentials of cells faster than a decrease in water potential of the surrounding environment to prevent a decrease in cell volume due to dehydration. Kadoya (1973) reported that the ${ }^{14} \mathrm{C}$ activity of the ethanol soluble fraction in the fruit increased in comparison with that of the ethanol insoluble fraction with decreasing moisture supply. The increase of the ${ }^{14} \mathrm{C}$ activity in the ethanol soluble fraction is thought to be an accumulation of solutes, consisting mostly of sugars and organic acids during osmoregulation in the vesicles. When translocation of photosynthate was studied using steady ${ }^{13} \mathrm{CO}_{2}$ feeding technique, Asakura et al., (1991) reported that water stress enhanced the rate of photosynthate partitioning in the fruit more than that of the leaf and stem, even though the amount of the total photosynthates in Satsuma mandarin was decreased under water stress conditions. Further, because fruit-thinning technique was used in mulchgrown plants in the present study, there were more leaves per fruit in the mulch treatment than in the control. It is possible that the sugar accumulation in the fruit is partially caused by both larger source activity and an increase of the partitioning rate in translocation of photosynthates into fruit under water stress in addition to active osmoregulation. However, monosaccharide accumulation in mulch-grown trees indicated metabolic changes in the process of osmoregulation in Satsuma mandarins.

\section{Literature Cited}

Asakura, T., K. Ogawa, H. Honjo, A. Suzuki, and T. Maotani. 1991. Analysis of photosynthate partitioning in water stressed Satsuma mandarin using steady state ${ }^{13} \mathrm{C}$ feeding technique. J. Jpn. Soc. Hort. Sci. 60 (Suppl. 2):22-23. (in Japanese).

Boyer,J.S. 1967. Leaf water potentials measured with a pressure chamber. Plant Physiol. 42:133-137.

Boyer, J.S. and E.B. Knipling. 1965. Isopiestic psychrometer for measuring leaf water potentials with a thermocouple psychrometer. Proc. Natl. Acad. Sci. USA 54: 1044-1051.

Chachin, K. 1986. Measurement methods for concentrations of organic acids, plant hormones, and enzyme activities in fruit, p. 155-177. In: S. Nakagawa (ed.). Laboratory manual for horticultural science. Yokendo, Tokyo. (in Japanese).

Cutler, J.M., D.W. Rains, and R.S. Loomis. 1977. Role of changes in solute concentration in maintaining favorable water balance in fieldgrown cotton. Agron. J. 69: 773-779.

Cutler, J.M., K.W. Shahan, and P.L. Steponkus. 1980. Influence of water deficits and osmotic adjustment on leaf elongation in rice. Crop Sci. 20: 314-318.

Daito, H. and Y. Sato. 1985. Changes in the sugar and organic acid components of Satsuma mandarin. J. Jpn. Sci. Hort. Sci. 54:155-162. (in Japanese).

Ehlig, C.F. 1962. Measurement of energy status of water in plants with a thermocouple psychrometer. Plant Physiol. 37:288-290.

Hashimoto, Y. and H. Nonami. 1990. Overview of current measurement techniques from aspects of plant science, p. 7-24. In: Y. Hashimoto, P.J. Kramer, H. Nonami, and B.R. Strain (eds.). Measurement techniques in plant science. Academic Press, San Diego, Calif.

Kadoya, K. 1972. Studies on the translocation of photosynthates in Satsuma mandarin: Effects of root environmental conditions on the translocation of ${ }^{14}$ C. J. Jpn. Soc. Hort. Sci. 41:361-366.

Kadoya, K. 1973. Studies on the translocation of photosynthates in Satsuma mandarin: Effects of water stress on the metabolism of sugars in the fruit. J. Jpn. Soc. Hort. Sci. 42:210-214.

Kaufmann, M.R. 1970. Water potential components in growing citrus fruit. Plant Physiol. 46:145-149.

Kriedemann, E. 1969. ${ }^{14} \mathrm{C}$ translocation in orange plants. Austral. J. Agr. Res. 20:291-300.

Meyer, R.F. and J.S. Boyer. 1981. Osmoregulation, solute distribution, 
and growth in soybean seedlings having low water potentials. Planta 151:482-489.

Morgan, J.M. 1984. Osmoregulation and water stress in higher plants. Annu. Rev. Plant Physiol. 35:299-319.

Nii, N. 1988. Anatomical aspects of juice sacs of Satsuma mandarin in relation to translocation. J. Jpn. Soc. Hort. Sci. 56:375-381.

Nonami, H. and J.S. Boyer. 1989. Turgor and growth at low water potentials. Plant Physiol. 89: 798-804.

Nonami, H. and J.S. Boyer. 1990. Wall extensibility and cell hydraulic conductivity decrease in enlarging stem tissues at low water potentials. Plant Physiol. 93:1610-1619.

Nonami, H., J.S. Boyer, and E. Steudle. 1987. Pressure probe and isopiestic psychrometer measure similar turgor. Plant Physiol. 83:592-595.

Nonami, H. and E.-D. Schulze. 1989. Cell water potential, osmotic potential, and turgor in the epidermis and mesophyll of transpiring leaves: Combined measurements with the cell pressure probe and nanoliter osmometer. Planta 177:35-46.

Sawamura, M., M. Nakashima, and Y. Osajima. 1975. Studies on translocation of ${ }^{14} \mathrm{C}$-labeled compounds from leaves to fruit in Satsuma mandarin. J. Agr. Chem. Soc. Japan 49:603-607.

Sharp, R.E. and W.J. Davies. 1979. Solute regulation and growth by roots and shoots of water-stressed maize plants. Planta 147: 43-49.

Sinclair, W. B. 1961. Organic acids and buffer properties, p. 161-190. In: W.B. Sinclair (ed.). The orange: Its biochemistry and physiology, Univ. of Calif. Press, Riverside, Calif.

Sugai, H. and H. Torikata. 1976. Effects of soil moisture content in early autumn on growth and juice constituents of Satsuma mandarin fruit. J. Jpn. Soc. Hort. Sci. 44:330-337.

Timpa, J.D., J.J. Burke, J.E. Quisenberry, and C.W. Wendt. 1986. Effects of water stress on the organic acid and carbohydrate compositions of cotton plants. Plant Physiol. 82:724-728.

Westgate, M.E. and J.S. Boyer. 1985. Osmotic adjustment and the inhibition of leaf, root, stem, and silk growth at low water potentials in maize. Planta 164: 540-549.

Wolf, A.V., G.B. Morden, and P.G. Prentiss. 1980. Concentrative properties of aqueous solutions: Conversion tables, p. D-227-D-276. In: C.W. Robert (ed.). CRC handbook of chemistry and physics, CRC Press, Boca Raton, Fla.

Yakushiji, H., H. Nonami, K. Sakai, T. Fukuyama, S. Ono, T. Yuasa, and Y. Hashimoto. 1992. Water-stress-resistant citrus seedlings suitable for fruit production under greenhouse and plant factory conditions. Acta Hort. 319:389-394. 